\title{
Guillotine side trimming shear machine: A case study of plate mill in Bhilai steel plant
}

\author{
Murli Krishan Bairagia ${ }^{a}$ Amit Kumar Sinha ${ }^{b^{*}}$ and Ankush Anand ${ }^{b}$
}

a Department of Mechanical Engineering, National Institute of Technology, Srinagar, India-190006 ${ }^{b}$ Department of Mechanical Engineering, Shri Mata Vaishno Devi University, Katra, India-182320

\begin{tabular}{|c|c|}
\hline$\overline{\text { A R T I C L EI N F O }}$ & A B S T RA C T \\
\hline $\begin{array}{l}\text { Article history: } \\
\text { Received 6 October, } 2015 \\
\text { Accepted } 23 \text { April } 2016 \\
\text { Available online } \\
24 \text { April } 2016 \\
\text { Keywords: } \\
\text { Trimming mechanism } \\
\text { Bhilai steel plant } \\
\text { Kinematics of machine } \\
\text { Shear force }\end{array}$ & $\begin{array}{l}\text { Double-sided trimming shear machine is used for longitudinal both-sided trimming of steel } \\
\text { plates and simultaneous scraping of trimmed edges at specific length. Side trimming shear } \\
\text { (STS) executes the most vital role in increasing the productivity of plate mill and due to its } \\
\text { feature, efficiency of plate mill division is enormously increases. In general, frequency of the } \\
\text { occurrence of breakdown in STS machine is a most challenging task when STS performs side } \\
\text { trimming and scrap cutting machining process. Bhilai Steel Plant (Steel Authority of India at } \\
\text { Bhilai) in India is continuously facing a problem due to breakdown of STS machine. The use } \\
\text { of separate knife for side trimming and scrap cutting reduces the possibility of scrap jamming } \\
\text { which is a major reason for breakdown of STS machine. Researchers and practitioners also } \\
\text { suggest the use of arc guillotine shear for side trimming and straight guillotine shear for scrap } \\
\text { cutting for minimizing the breakdown in STS machine. The aim of this study is to describe the } \\
\text { problems faced by the steel industry as well as the necessary steps which should be taken for } \\
\text { improvement of the productivity of STS machine and also it has made contribution to Bhilai } \\
\text { Steel Plant by its growth and prosperity. The methodology of study is purely qualitative and } \\
\text { the results point out the problems, its implications, steps taken to improve the overall } \\
\text { productivity of Bhilai steel plant. }\end{array}$ \\
\hline
\end{tabular}

\section{Introduction}

Bhilai steel plant (BSP) was established with Indo-Russian collaboration on March 2, 1955 (Roberts, 1983) which is the India's first and foremost manufacturing plant of steel plates as well as steel rails. In the present scenario, BSP is the eleven-time winner of prime minister's trophy for best integrated steel plant in India, it (BSP) achieves fourth position in world among top steel producers (Parry \& Strümpell, 2008). Bhilai steel plant is one of the integrated steel plants of Steel Authority of

* Corresponding author.

E-mail addresses: amitsinha5050@gmail.com (A. K. Sinha) 
India Limited (SAIL). BSP has all together 61 departments. Some of the important department of BSP are as follows: Coke oven batteries, Blast furnaces, Steel melting shop, Research and control laboratory, Blooming and billet mill, Merchant mill, Wire rod mill, Rail and structure mill, Plate mill, Coal chemical plant, Dust catcher department, Cast house, Gas cleaning section, Foundry shop, Forging shop, Continuous casting department, Oxygen plant, Propane plant, Sintering plant, Twin hearth department, etc. Fig. 1 illustrates the process flow chart of BSP, SAIL (SAIL, 2015; Kashyap, 2014). Out of 61 departments, Plate mill is one of the most important department. Side trimming shear (STS) machine which is installed in Plate mill department is continuously utilizing for longitudinal bothsided trimming of steel plates and simultaneous scraping of trimmed edges at specific length.

The productivity of Plate mill mainly depends upon the efficiency of STS machine. Therefore, minimizing the non-productive time of STS machine is a major challenging task for BSP. Although, there are a lots of reason for breakdown of STS machine but in this article we are mainly emphasizing the scrap jamming which is a major factor for breakdown of STS machine. In BSP, occurrence of frequent breakdown in STS machine decreases the productivity of Plate mill. Therefore, smooth functioning of STS machine is a major concern for any practitioners and researchers.

In this article, we conducted descriptive and experimental research for dealing how to minimize the breakdown in STS machine. The use of separate knife for side trimming and scrap cutting reduces the chances of breakdown in STS machine. This article also reveals some of the major reasons which are responsible for breakdown in STS machine.

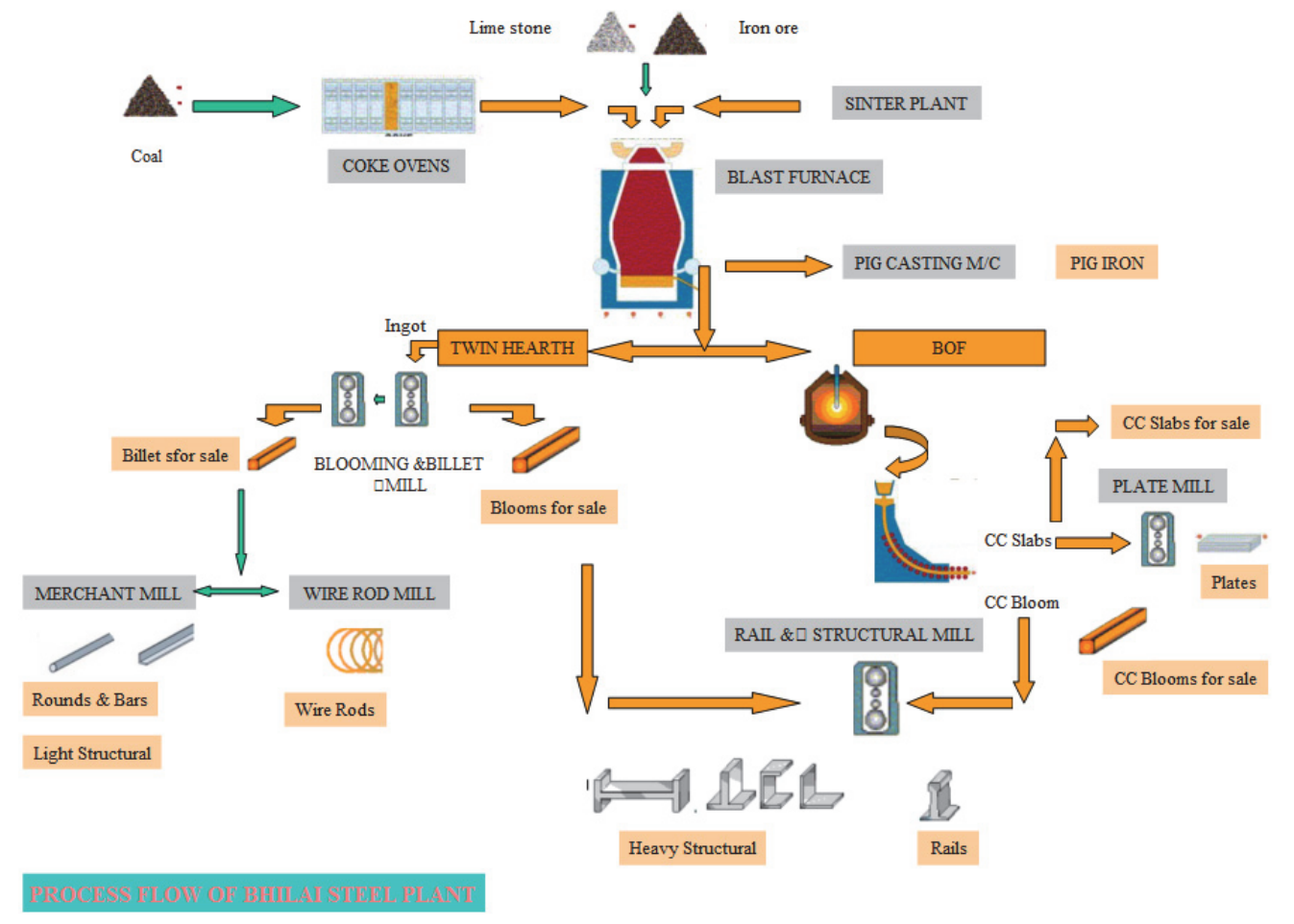

Fig.1. Process flow chart of SAIL Bhilai adopted from SAIL (2015)

\section{Literature survey}

Scrap jamming in STS machine is a major concer for conducting the research for any researchers and practitioner. Although, a lot of suggestions are suggested and some of the suggestion are implemented by some of the industries. But, it is hard to conclude that we already elliminated the possibility of scrap jamming in STS machine. Therefore, scrap jamming is a major concern for improving the productivity of STS machine. Improved version of rotary drum type shearing machine is discussed by Ito (1997) for cutting long hot rolled steel plate at very high speed. Moyer (1949) 
suggested a trimming machine which is more useful for trimmimng three edges of folded, multi-page booklet. Due to the above sugggested trimming machine papers and piles industries speedup exponentially. The contribution of Elwood (1950) accelerated the cutting/trimming operations in a shell drawn from a sheet metal. They implemented the concept of straight side wall haveing a sharp cutting edge for performing the machining operation.

Sewing, circular shearing, and guillotine shearing are the three most important mechanicsms which are utilized in metal tube industy for cutting metal tube. Although the most problem which is associated with guillotine shear cutting mechanism for cutting metal tube is the happeing of the partial crushing of the tube near the cutting-place and this partial crushing is responsible for occurrence of slightly folding near the end of cut tube. The presence of this slight fold narrows the free opening of the tube and impedes the introduction of balls during mounting on mandrel rods in cases where the two tube sections are to be subsequently drawn. This disadvantage can be overcome by using the sawing method, but saw cuttings adhering is a major challenging task in sawing mechanism for any practitioners and researchers.

Marcel (1962) suggested a new concept for preventing the deformation of metal tube by doing some improvement in guillotine shear cutting mechanism and they also found that due to this advancement, there were no saw cutting left. The new advancement of Marcel (1962) consists of a cutting tool which is utilized for cutting tool to use in shearing tube on guillotine shears. The salient characteristics of Marcel (1962) cutting tool is that the shearing members make two half V's which are joined together but they maintain their point offset relative to each other. On the basis of empirical relationship, it is quite clear that the points are offset by a distance at least equal to the wall thickness of the metal tube.

Side-stand, hold-down, blade carrier, top connecting plate, and bottom connecting plate are the major component of guillotine shear (Tozzo et al., 2014). The above suggested major components are responsible for vibration characteristics, factor of safety, rigidity and strength, dynamic stresses of the guillotine shear. Therefore, these components should be critically examined from time to time (Ramamurti et al., 1997).

There is limited literature based on design of plate working machine tools (Zhang \& Gao, 2014). However, some scholars (Ramamurti et al. 1992 and 1994) explain the basic conceptual design of threeroll plate bending machine and press brake of medium capacity. Ramamurti and Gowri (1996) illustrated statistical analysis of guillotine shearing machine. Ramamurti et al. (1998) presented two baisc model of guillotine shearing machines, first model based on the conceptual design with the drive shaft paraller to the blade and the other is perpendicular to the blade.

\section{Background of guillotine side trimming shear machine}

Nowadays, steel is the fundamental key for economic growth of any nation. In India, there are several steel manufacturers like Jindal Group, TATA Steel Group, JSW Steel Limited, Bhusan Steel Corporate Limited, etc. But, Bhilai Steel Plant is one of the best integrated steel plants of SAIL in India. Side Trimming Shear Machine is used for finishing the steel plates. It consist mainly four mechanism by which, after shearing or trimming, we get desired width of steel plates (Wang et al., 2014). The four most important mechanisms of STS machine are as follows (Boljanovic, 2014; Gustafsson \& Oldenburg, 2014):

- Counter Balance mechanism

- Vertical Gap mechanism

- Two-arm lever mechanism

- Horizontal Gap mechanism 


\subsection{Counter balance mechanism}

The schematic diagram of counter balance mechanism as well as vertical gap side trimming mechanism is illustrated in Fig. 2. Eccentric shaft with spherical roller and upper knife with knife holder act as a driver and driven systems, respectively. The driver is a major component of counter balance and vertical gap side trimming shear machine (see Fig. 2). When eccentric shaft rotates due to this spherical roller press the wedge goes downward. And, due to this downward force, one end of the hollow shaft which is attached to wedge as well as upper knife will move downward. The other end of the hollow shaft is attached with counter weight of approximate $500 \mathrm{~kg}$. The whole mechanism is mounted on anti-friction bearing (roller bearing) which will facilitate for see-saw mechanism. In counter balance mechanism the eccentric shaft that is driven by the bull gear is responsible for the downward movement of the upper knife for side trimming. Now for the upward movement of the upper knife we use a counter-weight which is attached at the other end of the shaft, connecting to the knife lever.

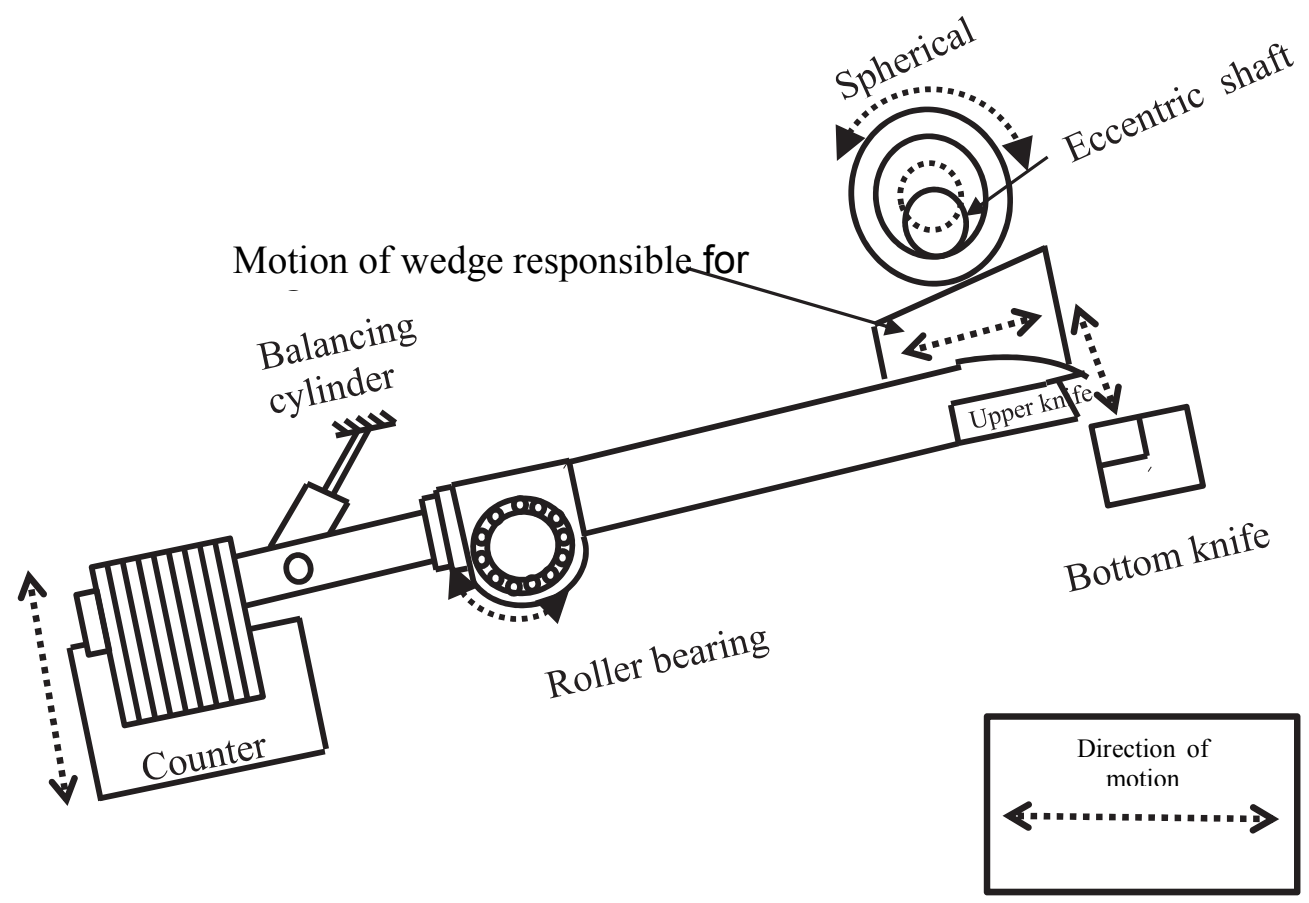

Fig. 2. Counter balance and vertical gap side trimming shear mechanism

Above, we already understand the concept of counter weight mechanism. Now the question is why we use counter weight for this specific mechanism? The answer is, there is no upward movement of upper knife so if we attached a dead weight to other side of hollow shaft then due to gravity upper knife will move upward and due to eccentric shaft upper knife will move downward. In Fig. 2, there is a balancing (hydraulic) cylinder whose purpose is to smooth this mechanism by adjusting the instantaneous pressure. So as the virtue of cutting force will be generate and cutting of steel plates takes place.

\subsection{Vertical gap mechanism}

Before starting the discussion of vertical or horizontal gap mechanism of STS machine we first understand the basic concept of horizontal and vertical gap. In this mechanism electric motor with screwed lever act as a driver and wedge mounted on hollow shaft acts as a driven system. Horizontal gap is the gap between the upper knife and bottom knife horizontally and vertical gap is the gap between the upper knife and bottom knife vertically with the reference as cutting edge of bottom knife. Vertical 
gap is illustrated in Fig. 3. Intentionally, we prove some oblique (3 to 4 degree) to upper knife with respect to bottom knife. Due to this oblique cutting of steel plate take place. The reason behind for providing some oblique is that this oblique decreases the point of contact in between upper and bottom knife which increases the shearing pressure for cutting steel plate. We have already discussed about vertical gap side trimming shear mechanism (shown in Fig. 2). Vertical gap is created by the motion of wedge which is clearly illustrated in Fig. 3. Electric motor is attached with screwed lever and the movement of this lever is creating horizontal movement of wedge. Due to the relative motion of wedge and spherical roller (see Fig. 2), upper knife goes downward and this downward movement of knife adjusts the vertical gap.

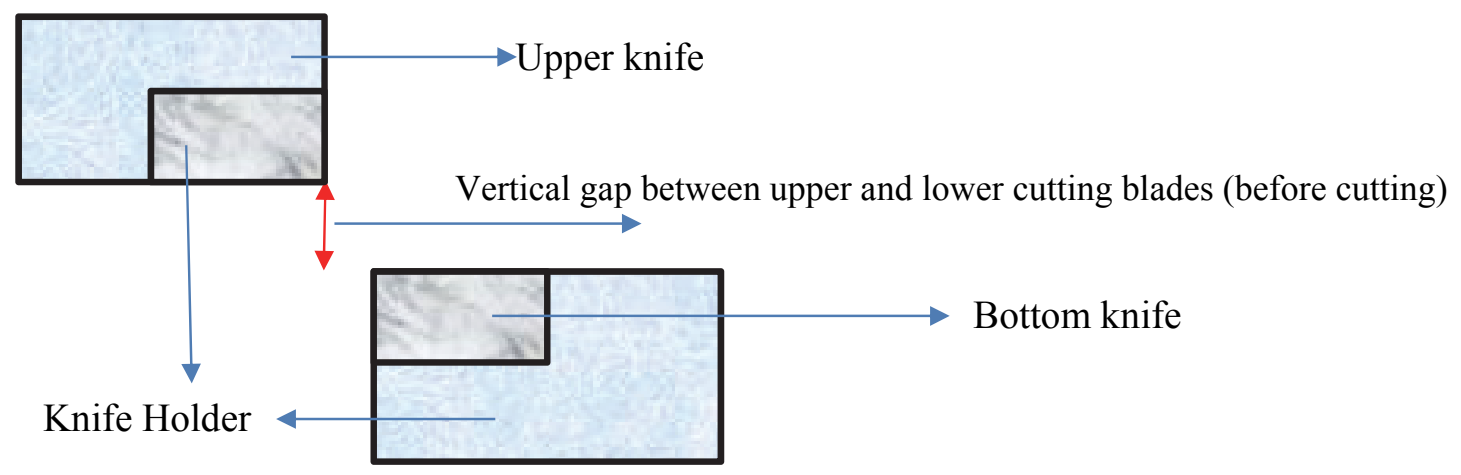

Fig. 3. Side view of cutting blades with vertical gap

\subsection{Two-arm lever mechanism}

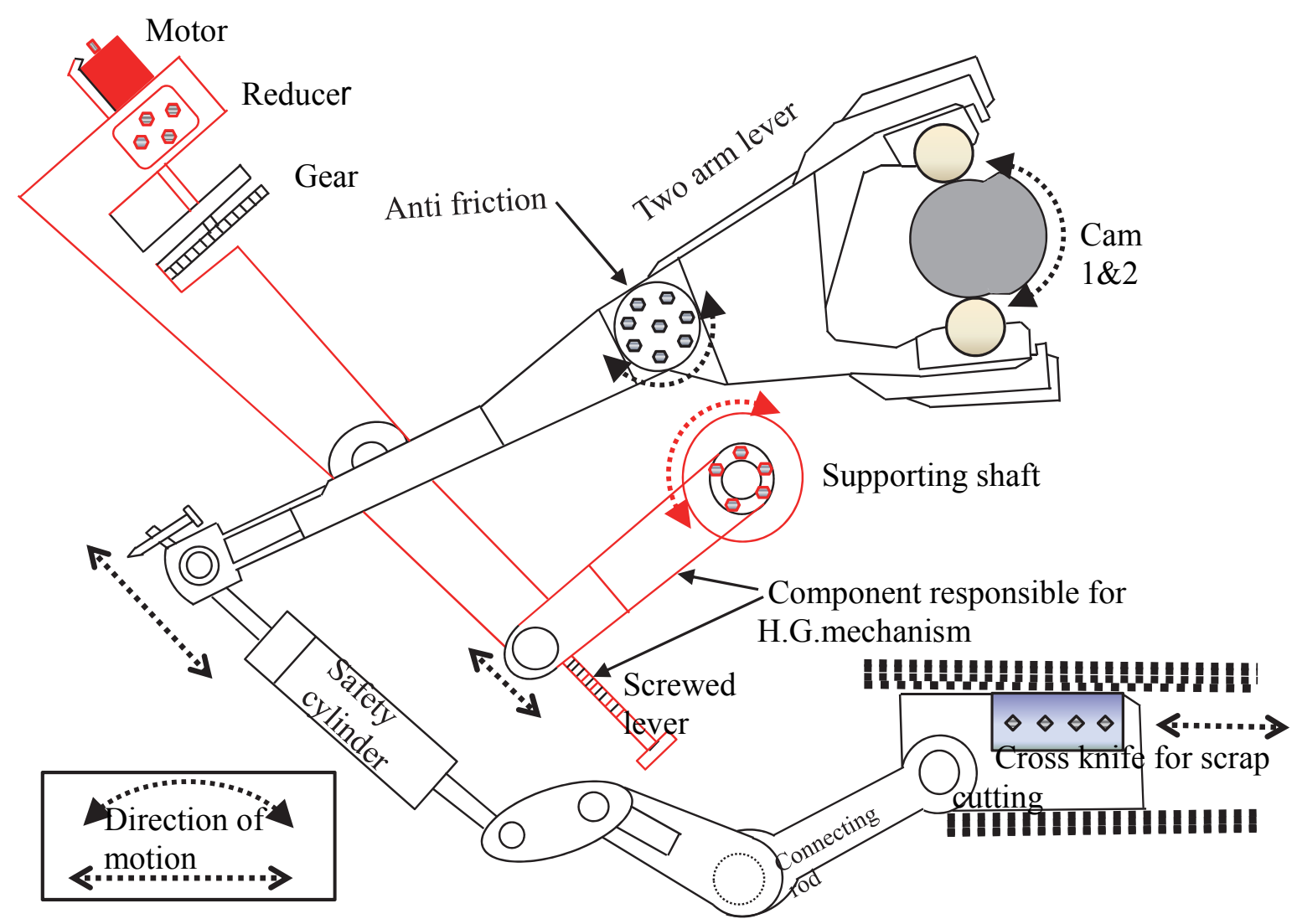

Fig. 4. Two-arm lever and horizontal gap side trimming shear mechanism 
Two-arm lever mechanism is used for scrap cutting. Two-arm lever is directly connected to main eccentric shaft with the help of two cams. Spherical roller and two cams (cam $1 \& 2$ as drivers) are surface-hardened. Two arm levers are situated on antifriction bearings on a journal which is fixed in the casing of the Side Trimming Shear. The arms of lever are having some alignment with respect to each other, due to this alignment the moment which is exerted on lever is reduced and the reason behind using two cams is to reduce the total load which is exerted on each cam. Instantaneous variable pressure which is generated in lever can be adjusted by hydraulic safety cylinder which is attached in other end of lever. In this way, one end of the hydraulic cylinder is attached with lever and another end is directly connected to cross knife with rigid links. Cross knife (as driven mechanism) for scrap cutting has only one degree of freedom. In this way two-arm lever mechanism is responsible for side trimming shear machine. Fig. 4 shows the schematic diagram of two-arm level and horizontal gap side trimming shear mechanism. Two arm lever, cam 1 and 2, anti friction bearing, safety cylinder, connecting rod, etc. are major component which facilitates the two-arm lever mechanism. All these components are shown in black color in Fig. 4. In this Figure, we can easily see that two-arm lever mechanism is responsible for scrap cutting. Scrap cutting takes place in stepping-scheme. Movement of cam 1 and 2 produced sliding-in and sliding-out of the cross knife and this mechanism is contributing for scrap cutting.

\subsection{Horizontal gap mechanism}

In this mechanism, electric motor connected with reducer box and upper knife attached with a small cam (inside casing of STS) act as driver and driven, respectively. Fig. 4 shows the schematic diagram of two-arm level and horizontal gap side trimming shear mechanism. Supporting shaft, screwed lever, motor, reducer etc. are responsible etc. are major component which facilitates the horizontal gap mechanism. All these components are shown in red color in Fig. 4. Side view of cutting blades with horizontal gap is illustrated in Fig. 5. Horizontal gap between the cutting blades is controlled by a screwed lever which is driven by an electric motor with the help of reducer box. Sliding arm will slide on the screwed lever during the revolution of screwed lever and the other end of the sliding arm is connected to a hollow shaft and inside the casing of STS a cam is attached to this shaft. When the shaft as well as cam rotates due to screwed lever then due to eccentricity of cam upper blade move horizontally and due to this whole mechanism, horizontal gap will adjust.

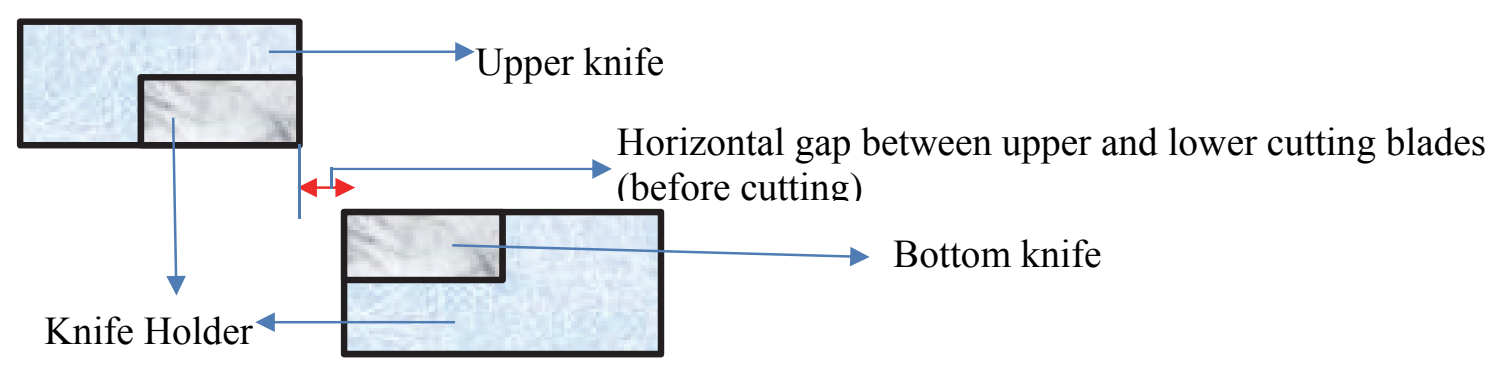

Fig. 5. Side view of cutting blades with horizontal gap (before cutting)

\section{Problem statement}

The products which are manufacture in BSP have wide range like thicker gauge plates, high tensile plates, ultra high strength plates, boiler quality plates, high strength pressure vessel quality plates, soft iron plates, wear resistant quality plates, rails, TMT bar, light structural's, bloom, beams, billets, crossing sleepers, angle, channel, slab etc. (Prasad and Usman 1984; John 2012; Plant 2014). Our research is based on STS Machine at Plate Mill division in SAIL Bhilai. The research is primarily based on the problem associated during side trimming and scrap cutting of steel plates. we observational training in SAL Bhilai and collected experimental data based on STS Machine of the Plate Mill division 
of SAIL Bhilai. In general, we observed that many times STS Machine did not work properly and breakdown occurs. This whole process was happened due to the scrap-jamming at the slot for scrap cutting and by virtue of STS Machine was out of order for 3 to 4 hours. As a result productivity of Plate Mill decreases exponentially. Therefore it is a big issues for practitioners and researchers that how to improve the productivity of STS Machine.

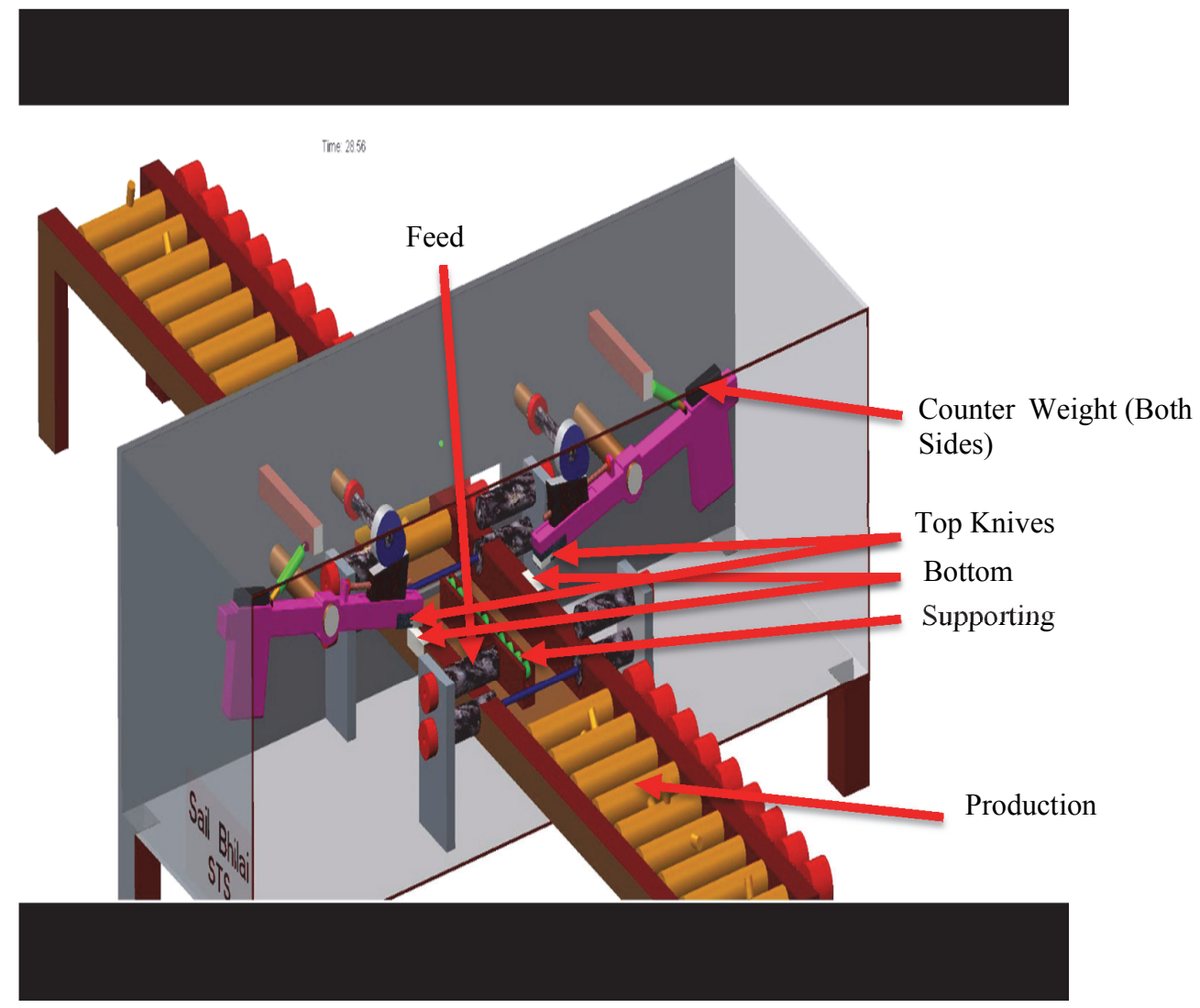

Fig. 6. Double-sided trimming shear machine

Double-sided trimming shear machine (see Fig. 6) is use for longitudinal both-sided trimming of steel plates and simultaneous scraping of trimmed edges at specific length. Side trimming shear (STS) executes the most vital role in increasing the productivity of plate mill. Counter balance mechanism, two arm lever mechanism, horizontal and vertical gap mechanism are important mechanism which illustrates the working principle of STS machine. Danieli Automation SpA is utilized for controlling the STS machine. Danieli Automation is an Italy based company which is a well know industry in automation and control.

\section{Solution approach}

STS machine in SAIL Bhilai is based on Russian technology and it was set-up in 1983. Therefore the technology which is utilized in STS machine is very old. Now it needs a well strategic approach for up-gradation of new technology in STS machine. The general purpose of STS machine is to cut the width of steel plate according to the requirement of customers which is known as side trimming as well as to cut the scrape from steel plates. In STS machine which is installed and working in Bhilai is performing both the operations side trimming and scrap cutting with the help of upper as well as bottom knife (see Figs. 3 and 5). Longitudinal cutting edge is used for side trimming and transverse cutting edge is used for scrap cutting. Although the productivity and efficiency of STS machine based on a lot of process variables but on the basis of observational training we are only interested to improve the productivity and efficiency of STS machine by reducing the scrap jamming because it (scrap jamming) 
is one of the important major factors for breakdown of STS machine. During our two month observational training we observed that almost $80 \%$ of the cases breakdown of the STS machine was occurring due to scrap jamming. Actually, in Bhilai's STS machine, we feed the steel plate with the help of feed roller when the position of upper knife is in above the steel plate then side trimming occurs due to longitudinal edge of upper knife and scrap cutting performs due to transverse edge of upper knife. In nut shell, only upper knife is performing for both the operations (side trimming, and scrap cutting). Therefore, probability or chances of scrap jamming in STS machine increases exponentially. However, if we use separate knife for side trimming and scrap cutting then the possibility of scrap jamming will be very less. If we use separate knife for scrap cutting and side trimming then both processes occurs with individual knifes. Based on the interviewing on the staffs and managers who are working in STS Machine at Plate Mill division in SAIL Bhilai, we also concluded that if we use arc guillotine shear for side trimming and straight guillotine shear for scrap cutting then the efficiency and productivity of the STS machine will improved tremendously.

\section{Conclusion}

The present article is based on observational studies of guillotine side trimming shear machine in BSP. The study reveals that scrap jamming in STS machine is a major challenging task in front of researchers and practitioners. Actually the major reason behind the scrap jamming is that same knife (only upper knife) is performing both the operations: side trimming and scraps cutting operations. Longitudinal edge and transverse edge of upper knife performs side trimming and scrap cutting operations respectively. Therefore, the performance and efficiency of STS machine is very poor which is installed in BSP. In this article we proposed two design improvements for guillotine side trimming shear machine which is as follows: (i) If we use separate knife for scrap cutting and side trimming then both processes occurs with individual knifes then the efficiency and productivity of the STS machine will improved; (ii) If we use arc guillotine shear for side trimming and straight guillotine shear for scrap cutting then the efficiency and productivity of the STS machine will improved tremendously. In future we hope that BSP will do some modification in the design aspect of guillotine side trimming shear machine for improving the efficiency and productivity of the STS machine. Apart from scrap jamming, there are some major factors that are responsible for low productivity of STS machine which gives an open platform for conducting research for practitioner and scholars.

\section{References}

Boljanovic, V. (2014). Sheet metal forming processes and die design. Industrial press.

Elwood, S., (1950). Trimming machine. US Patent 2,526,163.

Gustafsson, E., Oldenburg, M., \& Jansson, A. (2014). Design and validation of a sheet metal shearing experimental procedure. Journal of Materials Processing Technology, 214(11), 2468-2477.

Ito, K. (1977). Rotary drum type flying shear machine. U.S. Patent No. 4,058,041. Washington, DC: U.S. Patent and Trademark Office.

John, B. (2012). Analysis of effectiveness and outcome of organizational development interventions in Bhilai Steel Plant. PhD Thesis; School of Management Studies \& Research;MATS University, Raipur (India)

Kashyap, M.K., (2014). Report based on training presentation of bhilai steel plant; Retrived on $25^{\text {th }}$ Oct 2015 at:http://www.Slideshare.Net/mukeshkashyap4/bhilai-steel-plant-training-presentation,00329851

Marcel, T. (1962). Guillotine shears. U.S. Patent No. 3,040,611. Washington, DC: U.S. Patent and Trademark Office.

Moyer, C.L. (1949). Three-knife trimming machine. U.S. Patent No. 2,482,685. Washington, DC: U.S. Patent and Trademark Office.

Parry, J., \& Struempell, C. (2008). On the Desecration of Nehru's' Temples': Bhilai and Rourkela Compared. Economic and political weekly, 47-57.

Plant, I. S. (2014). Steel Authority of India Limited. Metallurgy, 155, 13. 
Prasad, J., \& Usman, M. (1984). Statistics for Iron and Steel: Industry in India. Steel Authority of India Limited.

Ramamurti, V., \& Gowri, S. (1996). Design considerations of over-crank and under-crank guillotine shears: a comparative study. Journal of materials processing technology, 57(3), 225-232.

Ramamurti, V., Rajaram, H., \& Balasubramaniam, M. (1998). Dynamic analysis of two types of overcrank guillotine shears - a comparative study. Journal of Materials Processing Technology, 83(1), 54-61.

Ramamurti, V., Rao, V. R. S., \& Sriram, N. S. (1992). Design aspects and parametric study of 3-roll heavy-duty plate-bending machines. Journal of materials processing technology, 32(3), 585-598.

Ramamurti, V., Sasikiran, S., \& Kumar, P. V. (1997). Dynamic analysis of a guillotine shearing machine. Journal of materials processing technology, 71(2), 202-214.

Ramamurti, V., Sreeram, P. N., \& Kannan, B. K. (1994). Design aspects and detailed study of medium tonnage mechanical press brakes. Journal of materials processing technology, 40(1-2), 99-110.

Roberts, W. L. (1983). Hot rolling of steel. CRC Press.

SAIL (2015); Retrived on $25^{\text {th }}$ Oct 2015 at:

http://www.sail.co.in/sites/default/files/plants/bhilai/bspflow.html

Thompson, A. G. (1960). High Productivity in heavy engineering. Iliffe.

Tozzo, C., Fiore, N., \& D'Andrea, A. (2014). Dynamic shear tests for the evaluation of the effect of the normal load on the interface fatigue resistance. Construction and Building Materials, 61, 200205.

Wang, Y., Yang, L., Gao, B., Shi, Y., \& Yuan, H. (2014). Experimental study of lateral-torsional buckling behavior of stainless steel welded I-section beams. International Journal of Steel Structures, 14(2), 411-420.

Zhang, J., \& Gao, J. (2014). The compensation study on blade gap during shearing process for swing shearing machine. China Metal Forming Equipment \& Manufacturing Technology, 2, 024. 